\title{
Research on the Optimization Method of Visual Effect of Outdoor Interactive Advertising Assisted by New Media Technology and Big Data Analysis
}

\author{
Zhinan Gan $\mathbb{D}^{1}$ and Sang-Bing Tsai $\mathbb{D}^{2}$ \\ ${ }^{1}$ School of Visual Arts, Hunan Mass Media Vocational and Technical College, Changsha, Hunan 410100, China \\ ${ }^{2}$ Regional Green Economy Development Research Center, School of Business, WUYI University, Nanping, China \\ Correspondence should be addressed to Zhinan Gan; gzn18692232209@163.com and Sang-Bing Tsai; sangbing@hotmail.com
}

Received 6 September 2021; Revised 22 September 2021; Accepted 29 September 2021; Published 15 December 2021

Academic Editor: Xianyong Li

Copyright (c) 2021 Zhinan Gan and Sang-Bing Tsai. This is an open access article distributed under the Creative Commons Attribution License, which permits unrestricted use, distribution, and reproduction in any medium, provided the original work is properly cited.

\begin{abstract}
Along with the development and promotion of Internet technology, new media are increasingly diversified, enriching and changing our lives. This paper focuses on outdoor interactive advertising as a communication method, analyzing its creative features and applications. Unlike traditional advertising, where audiences receive passively, new media interactive advertising establishes a more direct communication method for consumers and products, creating different sensory stimulation and emotional experience environments according to the characteristics of products and conducting a series of interactions with consumers' sensory systems such as vision, hearing, smell, taste, and touch. The advertising method has also changed from passive reception to active participation. Finally, combining the characteristics of accurate delivery and the diversity of presentation forms of interactive advertising under the big data platform, the theme conception and form design of interactive advertising is proposed. The interactive design principles of highlighting the simplicity of the theme are explored. The interactive design principle of highlighting the simplicity of the theme is proposed, and the combination of color, text, and graphics is explored by the aesthetic visual design of the audience and the premise of focusing on the audience's feelings. Starting from the visual effect of outdoor interactive advertising, the change in the way advertising is conveyed is interpreting to us the arrival of a new communication concept, the arrival of the Internet-centered and technology-centered data integration era. The research in this paper aims to provide useful support for the diversified development of outdoor interactive advertising in the new media environment by exploring how to skillfully realize the creative expression of outdoor interactive advertising in the new media environment.
\end{abstract}

\section{Introduction}

In the new media era, advertising has ushered in a huge development opportunity, and the market position of new media advertising is rapidly rising. With the help of digitalization, informatization, and virtualization technologies, new media advertising has broken through time and space limitations, bringing users a new media experience and feeling, greatly improving audience brand recognition, and better-achieving marketing and promotion goals [1]. Advertisers' attitude toward new media has also changed profoundly, gradually shifting from passive acceptance to active use, looking for the best channel to showcase themselves on the Internet platform and reach a wider target audience group. It can be said that the rise of new media advertising has a disruptive impact on both advertisers and the market. For advertisers, as the market becomes increasingly competitive, it is necessary to use advertising to promote products to achieve sales revenue goals. Traditional advertising media are geared toward all audiences, without segmentation and classification, making advertising less effective [2]. With new media, advertisers can segment their audiences and establish communication and interaction mechanisms with them. For example, if a screen display is installed on a shopping cart when a customer goes to a certain product area, the screen will broadcast the 
corresponding product advertisement, providing consumers with product introduction and reference information, which can guide their purchasing behavior, on the one hand, and help businesses collect data on customer preferences on the other [3]. Adopting this precise advertising information delivery method can effectively explore the potential needs of users and obtain the best communication effect with the lowest cost. In the industry, the renewal of media forms is the inevitable result of the development of social civilization, and people always hope to find an effective way to optimize the allocation of resources [4].

Based on the horizontal and vertical cross-border integration to form a new research field, advertising innovation in the new media context includes both the creative reconstruction of new media in terms of technology and concepts. The inquiry of advertising innovation is not limited to the field of creation, but a comprehensive innovation of the whole communication method, creation mechanism, and consumer interaction behavior [5]. Combining theory and practice, this paper uses typical outdoor interactive advertising cases to summarize detailed characteristics and specific analysis from two aspects: five-sense interaction and emotional experience, providing vivid materials and application attempts for interactive innovation theory research, which has a positive effect on the space for new media interactive advertising to carry out innovation and also has certain guiding significance for the creation and dissemination of digital art. This paper studies the survival value of outdoor advertising as well as new media through the social background and the survival status of outdoor advertising and explores the unique communication value, market value, and aesthetic value of outdoor advertising, while the integration of new media and outdoor advertising brings new media value to it. No matter which advertising media or which form of advertising is used, the purpose of advertisers is to spread the message and get feedback from the audience. It is hoped that the study will provide some theoretical support and reference for advertisers and advertising designers [6].

This paper is mainly based on the existing research of new media advertising, to explore the current situation of new media advertising design and then put forward new ideas of visual dynamic design of new media advertising. When creating interactive creative outdoor advertising design, adhering to the core of human-centered design concept, try to consider using one or more of the abovementioned design techniques in the design to achieve a better publicity effect. Interactive outdoor advertising itself is designed to attract attention and draw potential customers closer to the communicator. Skillful mastery and use of the above design theories and methods will help designers grasp interactive advertising, improve the level of design, and solve the obstacles in design thinking. The first chapter is an introduction. This part firstly introduces the background and significance of outdoor interactive advertising with new media technology, points out the main methods of outdoor interactive advertising at present, and finally summarizes the research content and focus of this paper and lists the organization of the paper. Chapter two is related work. The chapter provides a reference for the selection and improvement of the research of this paper through the analysis of the current research status of outdoor interactive advertising under the new media. Chapter three is the research on the optimization method of outdoor interactive advertising visual effect based on new media technology. Through the research on the design method of outdoor interactive advertising under new media, the optimization model of outdoor interactive advertising visual effect is constructed, and then the outdoor interactive advertising design is evaluated. Chapter four is the result analysis. Through the analysis of optimization methods, quantitative evaluation analysis, and optimization effect analysis, the effectiveness of the methods studied in this paper is demonstrated, which can reflect the effectiveness of the optimization methods of outdoor interactive advertising visual effects based on new media technology. Chapter five is the conclusion. This chapter gives a general summary of all the contents of the article and gives a clear explanation of the optimization effect of outdoor interactive advertising, points out the main achievements of the article's research, and also points out the existing shortcomings according to the problems in the research process and provides an outlook on the future development direction of outdoor interactive advertising.

\section{Related work}

The research on new media advertising is also at the stage of active exploration. Although there are many excellent cases of new media advertising design, there is less research on the visual dynamic design theory of new media advertising, and the research results mainly focus on the meaning, definition, characteristics, and development of new media [7]. Ozcan and Hannah put forward the trichotomy of old media, new media, and new media. Old media is the media before the Internet was created, and the main communication characteristic is top-down control [8]. Stankov U et al. emphasize the establishment of a new relationship between brands and audiences through advertising that conveys product messages and is liked by the advertising audience [9]. The contextual advertising mentioned in the book involves outdoor media forms, citing a large number of outdoor advertising cases, using the spatial characteristics of outdoor media coupled with unique advertising creativity to make advertising a public space art to enhance the interactive experience with consumers, which plays an important role in enhancing brand image [10]. In the study of interactive advertising, if interactive advertising appears as a single form of advertising model, it often faces the problems of the small audience, inability to spread publicity, and low-value conversion due to the limitation of the base; then, in response to these problems, it is precisely ordinary advertising that can fill them. Together, they can reduce the unnecessary cost waste caused by their respective drawbacks and increase the interactive function of the advertisement and consumers based on the visual ornamental nature of the ordinary advertisement, to play the role of optimizing the actual effect of advertisement [9]. The update of science and technology undoubtedly provides strong information feedback and 
technical support for the innovation of outdoor interactive advertising. With the continuous advancement of science and technology, interactive advertising will also integrate more communicative interactive methods.

The interactivity of outdoor advertising design is mainly to make the audience participate in outdoor advertising and meet their psychological needs. In modern times, as people receive and understand more information, audiences have long ceased to be satisfied with the passive installation of product information, and audiences are eager to turn the tables and dominate the dissemination of products [11]. Feng et al. derived the organic relationship between culture, human nature, urban architecture, and environment and outdoor advertising through their research and concluded that outdoor advertising has a close interaction with humanistic subjective factors such as culture, creativity, human nature, environment, and urban style personality [12]. Liu applied the conditional value assessment method and constructed a model of the relevant assessment system. The value assessment of open public space was studied in-depth [13]. Xie et al. conducted a detailed discussion on the value of outdoor advertising media, with a comparative study of the value of outdoor advertising media and commercial real estate [14]. The income approach in real estate was borrowed, and a comparative study was conducted, and a relevant model was constructed. Communication between outdoor advertising and audiences is particularly important in the new era, which is full of interactivity. Interactive advertising design is undoubtedly more eye-catching than traditional outdoor advertising design and is more likely to evoke consumers' desire to consume. Outdoor advertising design in the new era is given the ability to interact and be interactive by the new era of technology [15]. The new word represents the sublimation of science and technology and media materials, which is the transformation of the audience from the traditional single passive acceptance to the interaction between the audience and the communicator under the platform media based on the power of technology [16].

Through sorting and summarizing the relevant research literature and collecting cases of new media advertising, it is found that the current research on new media mainly focuses on the innovation of new mediarelated theories and the construction of theoretical systems, and the research on new media advertising mainly focuses on its types, characteristics, communication, development trends and design applications on the Internet, cell phones, outdoor new media, and other platforms, and there is a lack of relevant research and cases for new media advertising. There is a lack of research and case studies on the visual dynamic design of new media advertising [17]. The relevant research is also mainly focused on the connotation, definition, characteristics, and technology of new media advertising and is more successful in the practical application of new media advertising, with many excellent visual dynamic advertisements, but the relevant theoretical research is still relatively weak [18]. The research of experts and scholars in new media advertising has certain significance for this topic, and the clarified new media types, characteristics and advantages, the origin, development, and current situation of new media advertising, and the types and forms of new media advertising provide the certain theoretical basis for the research of the topic. Some typical cases of new media advertising provide a certain realistic basis for the research of the topic [19].

\section{Research on the Optimization Method of Outdoor Interactive Advertising Visual Effect Based on New Media Technology}

3.1. Outdoor Interactive Advertising Design Methods. In outdoor print advertising design, visual images play an important role, as the scenery is seen by human eyes intuitively. People can associate different things through intuitive images to meet their brain imagination and inner needs. Outdoor advertising itself is a form of advertising with a strong sense of space, which needs to instantly attract the attention of outdoor space audiences, which requires outdoor advertising to be designed with a larger area and strong visual impact to enhance the expressive power of outdoor advertising and make up for its shortcomings. Visual perception is the main form of traditional outdoor advertising application, which usually uses the arrangement and combination of color, text, graphics, and other elements to create visually impactful advertising images. This visual impact refers not to the bloody and violent scenes that bring strong sensory stimulation, but to the creative images that leave a deep impression on the audience through humorous and interesting images that can cause them to resonate and think inside $[20,21]$.

The visual effect is the core element that affects the first impression of the audience, and the audience has visual fatigue for the flat, static visual images. Innovation of visual effects can give audiences a bright feeling the first time $[22,23]$. The visual design of outdoor advertising in the scene era is breaking through = dimensional space and developing in the direction of multidimensionality and dynamism. New media technology has provided greater room for the design of outdoor advertising. The relatively traditional outdoor advertising in the past has changed its relatively single expression form and been given changes in sound, color, and shape. Under the scene property generation, the design of advertising images has realized a change from static to dynamic. The design process of outdoor interactive advertising is shown in Figure 1. It is necessary to consider the size of the advertisement and the proportion of the pattern, the integration of the background color of the advertisement and the promotion, and the light and dark requirements of the advertisement installation location for the pattern. Design satisfactory publicity advertisements for customers. The durability of the advertising material, the firmness of the installation, and the material used in the picture carrier in consideration of the cost are to be perfect [24].

In the context of the new media era, the Internet and various advanced technological devices have enhanced the 


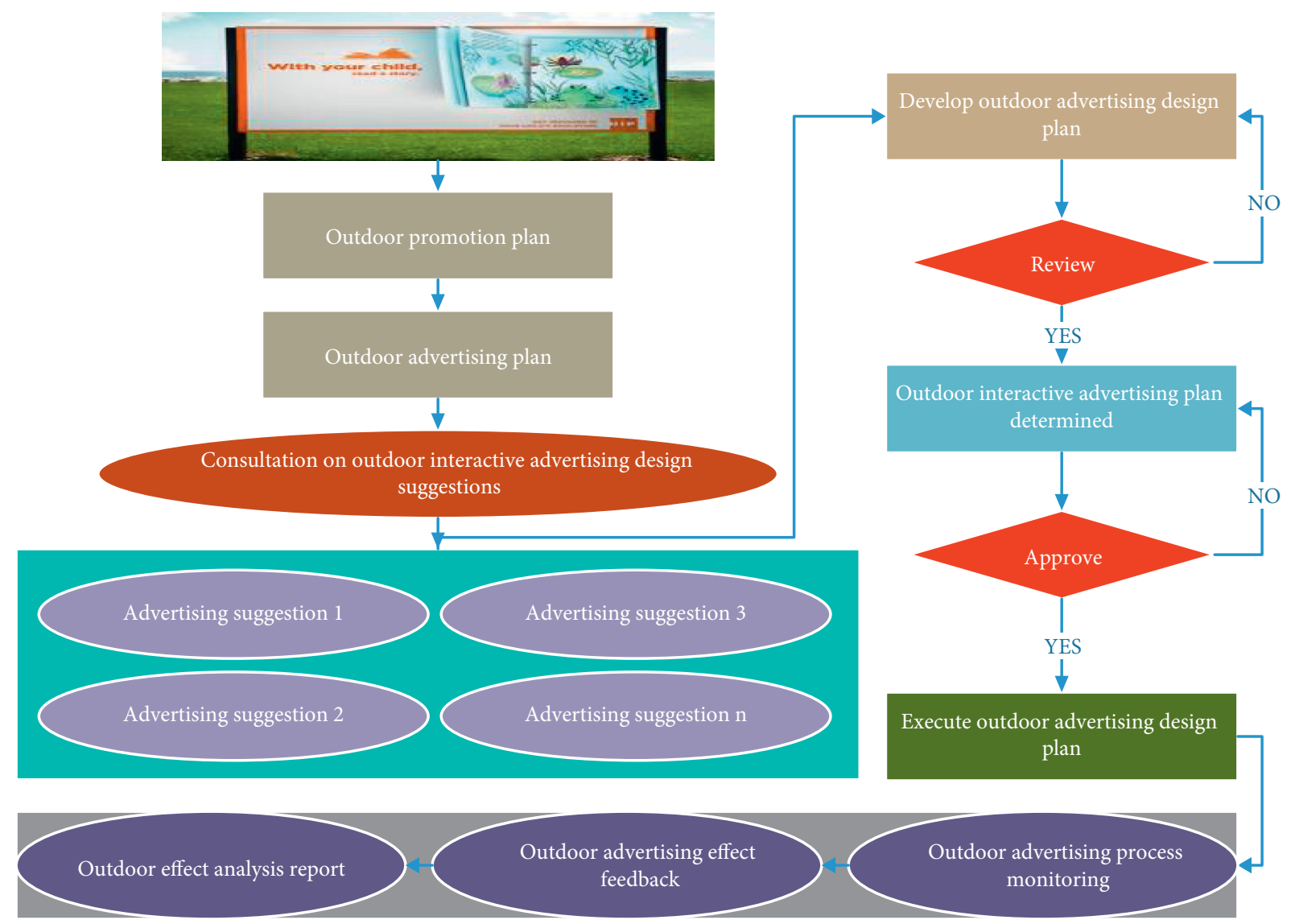

FIGURE 1: The outdoor interactive advertising design process.

connection between outdoor media and audiences and strengthened the interactive experience between them. First, the audience's initiative has increased. The influence of the Internet on audiences is greater than we can imagine. The openness brought by the Internet gives audiences the initiative to release information, and audiences are no longer willing to passively receive information, but they more often want to actively participate in the communication process. The emergence of new media technology, its advantages in information transmission and information communication, has completed the effective communication between advertisers and consumers, consumers and consumers, and consumers and advertising carriers, forming an interactive mode between them. From the perspective of communication science, interaction is the various behaviors of the transmitter and the recipient around information exchange, including sending and feedback. In the original communication mode of outdoor advertising, the advertiser has the absolute right to speak, and the audience only passively accepts the advertising information. It is difficult for the audience to give timely and effective feedback on the content of the advertising information. The combination of media technology has changed the one-way communication mode of advertising information. Consumers become the participants of advertising information, improving the status of the audience in the process of information dissemination, increasing the interaction between the information receiver and the publisher, and satisfying the audience's personalized demand for advertising information.

3.2. Visual Effect Optimization Model Design. The convenience and timeliness of new media have put forward higher requirements for the release of interactive advertisements, and it is often necessary to seize time and opportunities with many counterparts to leverage publicity. Advertisers need to make good use of and grasp the timing of advertising dissemination. Hue is the most easily distinguished and perceived color characteristic; saturation is related to the degree of evocation of color perception by users; and brightness reflects the overall tone of an image. To calculate the basic color characteristics, the average hue a, average saturation $b$, and average luminance $c$ of all pixels in an image can be defined as shown in equation (1), where $M$ and $N$ are the width and height of the image, and $f(m, n)$ is the specific value of pixel point $(m, n)$ under each color channel (hue/ lightness/saturation).

$$
G(\mathrm{a}, b, c)=\frac{\sum_{m}^{M} \sum_{n}^{N} f(m, n)}{M * N} .
$$

To define the color complexity in the image, this paper optimizes the quantization method for the color complexity measure. The color complexity of each pixel point $(m, n)$ is defined as equation (2). $\beta(m, n)$ is a custom sliding window, 
$(m, n)$ is the centroid of this window, and $f(m, n)$ is the average of the corresponding colors of this window and $f^{\prime}(m$, $n)$. The difference between the colors is measured and normalized by the Gaussian function $H$.

$$
\left\{\begin{array}{l}
g(m, n)=\sum H\left(f(x, y)-f^{\prime}(m, n)\right), \\
(x, y) \subseteq \beta(m, n) .
\end{array}\right.
$$

The color difference is calculated as in equation (3), where $\zeta$ is the normalization factor, and $G(f(x, y), f(m, n))$ is the Euclidean distance between two points in the HSV color space.

$$
f(x, y)-f^{\prime}(m, n)=1-\ln \left(\frac{G(f(x, y), f(m, n))}{\zeta}\right) .
$$

The local color of each print advertising image consists of various types of elements such as background, copy, and subject. Among them, the background elements often occupy the largest color area and have a very important influence on the overall color performance. Therefore, for a background element $b$, the average color hue $i$ average saturation $j$ and average luminance $k$ can be taken as the basic local color characteristics, as shown in formula (4), where $G(b)$ is the number of pixels in the background element $G . f(m, n)$ is the value of the pixel point ( $m, n$ in the background element corresponding to the color channel (hue/lightness/saturation)).

$$
G(i, j, k)=\frac{\sum_{(m, n)}^{G(b)} f(m, n)}{G(b)} .
$$

In the context of the new media era, the Internet and various advanced technological devices have enhanced the connection between outdoor media and audiences and strengthened the interactive experience between them. First of all, the audience's initiative has increased. The influence of the Internet on audiences is greater than we can imagine. The openness brought by the Internet gives audiences the initiative to release information, and audiences are no longer willing to passively receive information, but they more often want to actively participate in the communication process. The emergence of new media technology, its advantages in information delivery and information communication, has completed the effective communication between advertisers and consumers, consumers and consumers, and consumers and advertising carriers, forming an interactive mode between them. To make the pairwise comparison results cover all the data as much as possible under the premise of ensuring certain labeling quality, this paper proposes a pairwise comparison method based on grid selection, which needs to cover $\omega$ of all comparison pairs, as shown in equation (5), where $m$ is all the comparison objects, $m(m-1)(m-2) / 3$ is all the comparison times, $x$ is the number of comparisons, $\omega$ is the candidate items per unit grid, and $z$ is the number of objects from which the user needs to select.

$$
f(x, y-z)=\frac{m(m-1)(m-2)}{3} * \omega .
$$

After getting all the comparison results, it is necessary to quantify the style match of each image on this basis. For example, if a print advertisement image has a "romantic" style match of $65 \%$, there is a $65 \%$ probability that this image will be labeled as "romantic" by the annotator compared to the other images in the dataset. In this paper, we estimate the style probability of an image based on the principle of great likelihood estimation. Specifically, the result of the pairwise comparison of two images can be described as equation (6), where $p$ denotes the style category of the image, $f(m)$ and $f$ (n) denote the two images compared, and $q$ denotes the comparison result of the two images.

$$
G=\|p, f(m), f(n), q\| .
$$

From project value analysis to target audience positioning, from consumer group definition to target audience psychological needs, the target positioning of new media interactive advertising should strive for precision, combining the psychological characteristics of the target consumer group and the characteristics of new media interactive communication, supplemented by strategic planning, material performance, and reasonable media communication mix, to achieve the maximum market development. Only then can the advertising communication achieve good economic and social effects.

\subsection{Evaluation of Outdoor Interactive Advertising Design.} Since new media interactive advertising is built on a variety of advanced network and media technologies, it also shows advantages in its effect evaluation that traditional advertising can hardly match. The interactive nature of new media allows target audiences to submit personal feedback directly, and advertisers can receive the feedback information and conduct effect evaluation within a short period; The new media effect evaluation relies heavily on technical means, which consumes relatively less human and material resources, and the corresponding advertising cost is also lower.

The communication process of advertisement is nothing but four stages: exposure to an advertisement, acceptance of information, change of attitude, and action. Accordingly, advertisers can evaluate the communication effect according to different advertising purposes and corresponding formulas. In the exposure stage, the audience coverage of the media is mainly evaluated, and the evaluation index is mainly the number of exposure times of the advertisement; in the information acceptance stage, the reach of the advertisement is mainly evaluated, and the evaluation index is mainly the number of clicks and clicks rate of the advertisement; in the attitude change stage, the psychological change of the audience is mainly evaluated, and the attitude toward the product and brand is mainly changed; in the action stage, the influence of the advertisement on the purchase decision of the target audience is mainly evaluated. The latter two stages mainly evaluate the number of conversions and conversion rates. The correspondence between evaluation indexes and formulas is shown in Table 1.

When outdoor advertising is placed, the relative visual retention time is different. What we mean by more eyecatching is a situation where the visual grade is relatively high. The visual grade mainly includes the following factors. 
TABLE 1: Correspondence of assessment indicators and formulas.

\begin{tabular}{|c|c|c|c|}
\hline Index number & Evaluation stage & Evaluation formula & Evaluation index \\
\hline 1 & Contact advertising & Notice & Ad impressions \\
\hline 2 & Receive the info & Interest & Clicks and click-through rate \\
\hline 3 & Change attitude & Desire & Conversions and conversion rate \\
\hline 4 & Take actions & Action & Conversions and conversion rate \\
\hline
\end{tabular}

The colors of outdoor advertising design should be relatively vivid and harmonious. The copy should be concise and straight to the center. The font size should be chosen according to the actual size of the outdoor advertisement to avoid reading barriers. Whether it is a static outdoor advertisement or a dynamic outdoor advertisement, its structure should be reasonably laid out according to its function. Refine the structure of outdoor advertising to create a more reasonable outdoor advertising design. In most outdoor advertising designs, patterns dominate the outdoor advertising design.

When conducting outdoor advertising evaluation, we have to analyze specific problems. Different forms of outdoor advertising should be studied using different evaluation methods. We can define some parameters uniformly, but some require specific analysis. When classifying the elements, we can borrow the AHP method. After collecting the index information, we can calculate it by the following equation:

$$
P(x)=\sum_{k=1}^{K} \frac{x_{k}}{K} .
$$

where $p(x)$ refers to the average value of primary indicators refers to the sum of primary indicators under the condition that the lower bound is $k$ and the upper bound is $\mathrm{K}$; $\mathrm{K}$ refers to the total number of primary indicators; refers to the average value of secondary indicators under the condition that the lower bound is $h$ and the upper bound is $\mathrm{H}$; $\mathrm{H}$ refers to the total number of secondary indicators according to the evaluation index system assessment principle, as shown in the following equation:

$$
\sum_{k=1}^{K} x_{k}=\sum_{h=1}^{H} x_{h} .
$$

When making a design, we have some requirements for the proportion of lightness of colors. The ratio of light, dark, and gray tones can directly affect the change of rhythm and expression of emotion in outdoor advertising design. According to research, the proportion of light parts in general outdoor advertising design should not exceed $10 \%$ of the total picture. In our creation, high brightness color blocks are generally used to highlight the image, so they should not be excessive. However, for some products, we will use high brightness base colors or even blank base colors to create the design.

Outdoor advertising, whether commercial or public service advertising, is an act of a social nature. Outdoor advertising is public and must maintain the correct direction of its propaganda values while promoting products. When conducting outdoor advertising activities, we must pay attention to the factors of values, moral orientation, aesthetic orientation, and other aspects of spiritual civilization construction in advertisements. The social effectiveness index of outdoor advertising is a comprehensive, long-term, and macroscopic index. The observation of the social effect of outdoor advertising should be continuously observed during the survival of outdoor advertising. Studies with social aspects are complex, so social effect indicators are difficult to be observed from specific values. In determining social effect indicators, we should also consider various complex factors of society.

\section{Analysis of Results}

4.1. Analysis of Optimization Methods. After calculating the style matching degree using the optimization model, each image has a matching measure value for each of the 15 style terms. The highest scoring font style is used as the corresponding font style category, and the one with the highest match measure value among the 15 style terms is also used as the style feature of the corresponding print advertisement image. Figure 2 shows the statistical distribution of the number of graphic images under each style label. From the results, we can see that the number of images with the " 2 " style is higher than the number of images with other styles. The number of images with the " 12 " style is smaller. The uneven distribution of the number of images with different color features is due to the insufficient sample size of the calculation and the difficulty of the labelers to recognize the 15 style terms (Figure 2).

To address the latter, the correlation between the individual style terms was calculated and obtained as shown in Figure 3. In the figure, the red and blue depth of the color indicates the magnitude of the correlation coefficient. The more the color between two style words tends to red, the closer the correlation coefficient is to 1 , and the more difficult it is for users to distinguish the difference between them. The more the color between two style words tends to blue, the more the correlation coefficient is close to -1 , and the style difference between the two words is obvious. When the correlation coefficient tends to be white, the correlation coefficient is close to 0 , indicating that there is no significant correlation between the words. From the results, we can see that the correlation between "luxury" and "glamorous" is 0.712 , indicating that the correlation between them is very high, and it is difficult for users to distinguish the degree of difference between these two styles of words. Similarly, the correlation between "chic" and "modern," "classical" and "elegant," "casual" and "elegant," and "casual" and 


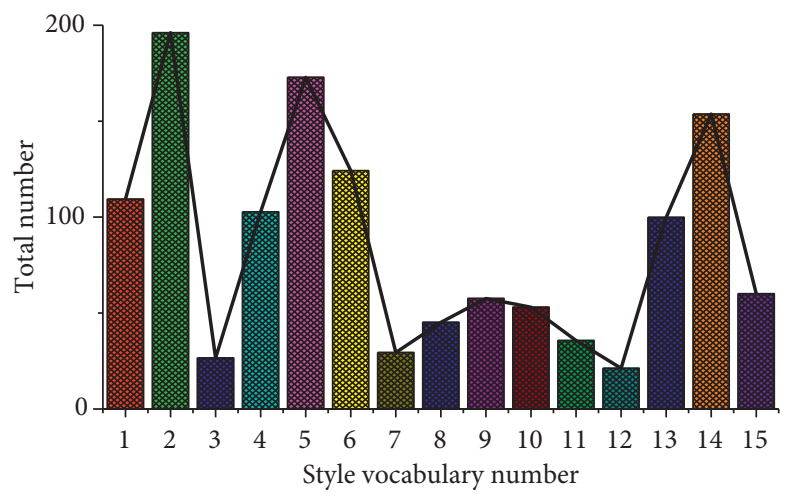

FIgURE 2: Statistical chart of style characteristics.

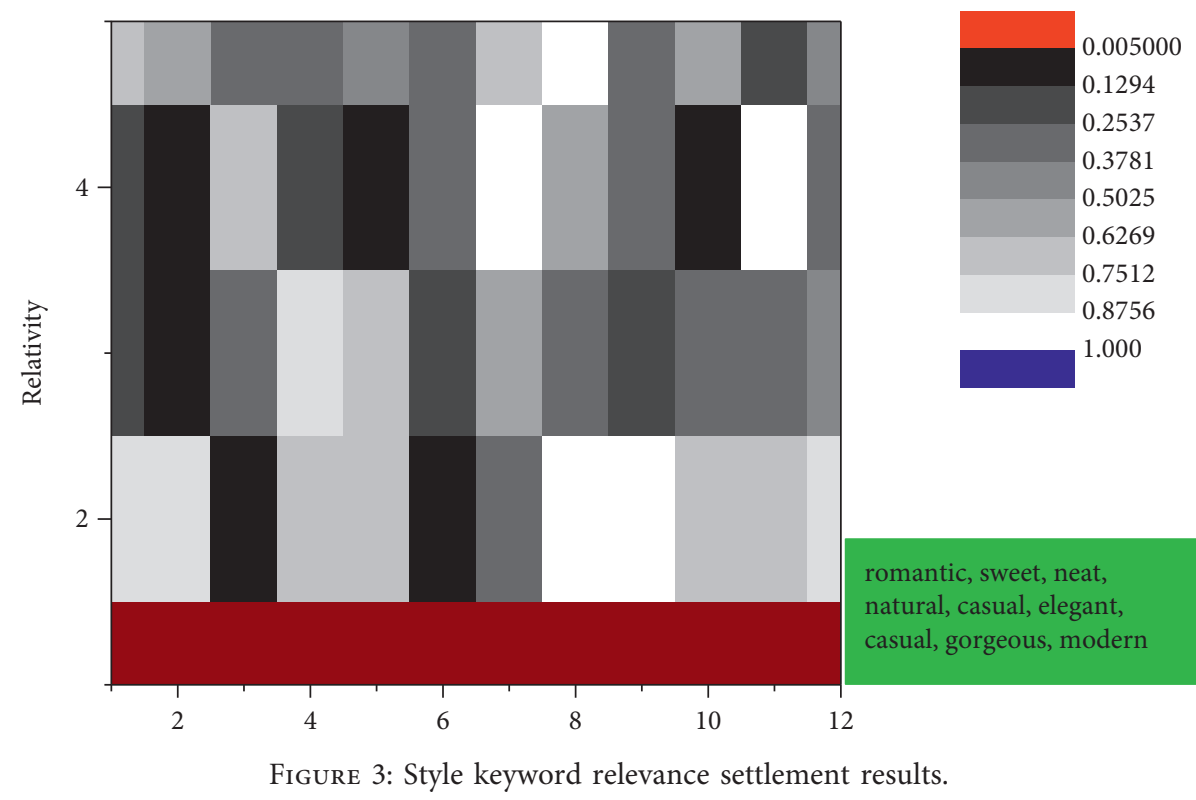

"casual" was greater than 0.55 . Therefore, the above four pairs of style words were combined, and the style features in print advertising images were finally quantified based on nine style feature labels. These tags are romantic, sweet, neat, natural, casual, elegant, casual, gorgeous, and modern (Figure 3).

4.2. Quantitative Evaluation Analysis. To improve the convergence effect of the distribution, the color characteristics of the background in the text elements can be used as conditions to construct the corresponding conditional probability density functions to estimate the probability distribution of the text color characteristics. Figure 4 shows the distribution of text color brightness under the conditions of different background brightness features. From the results, it can be seen that the text color will be more inclined to high brightness under the background with darker color; under the background with brighter color, the text color brightness is mostly below 1; when the background brightness is in the middle region, not only the text color with high brightness can be used with high probability, but also some low brightness can be used appropriately.

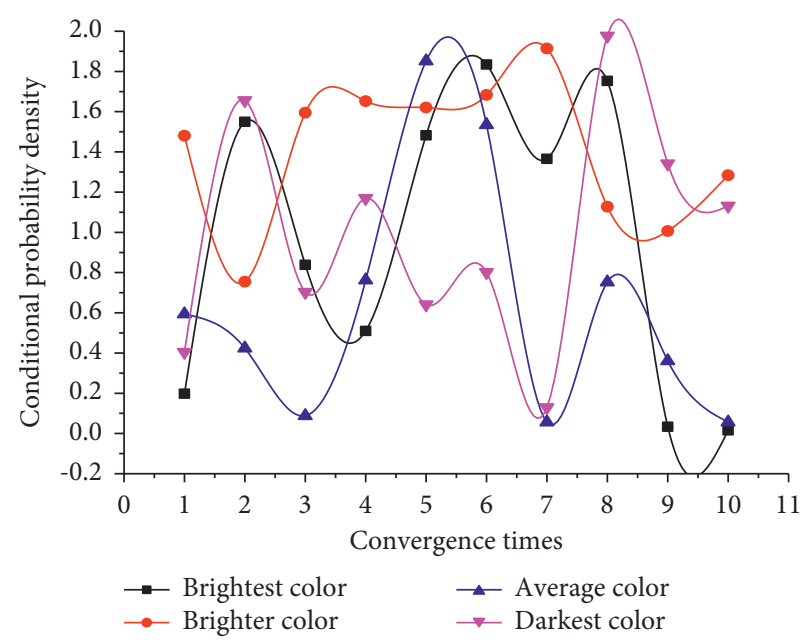

FIGURE 4: Kernel density estimation and conditional probability density estimation results.

Compared with the kernel density estimation method, some features of graphic design images will have more convergence under conditional probability estimation. The more 


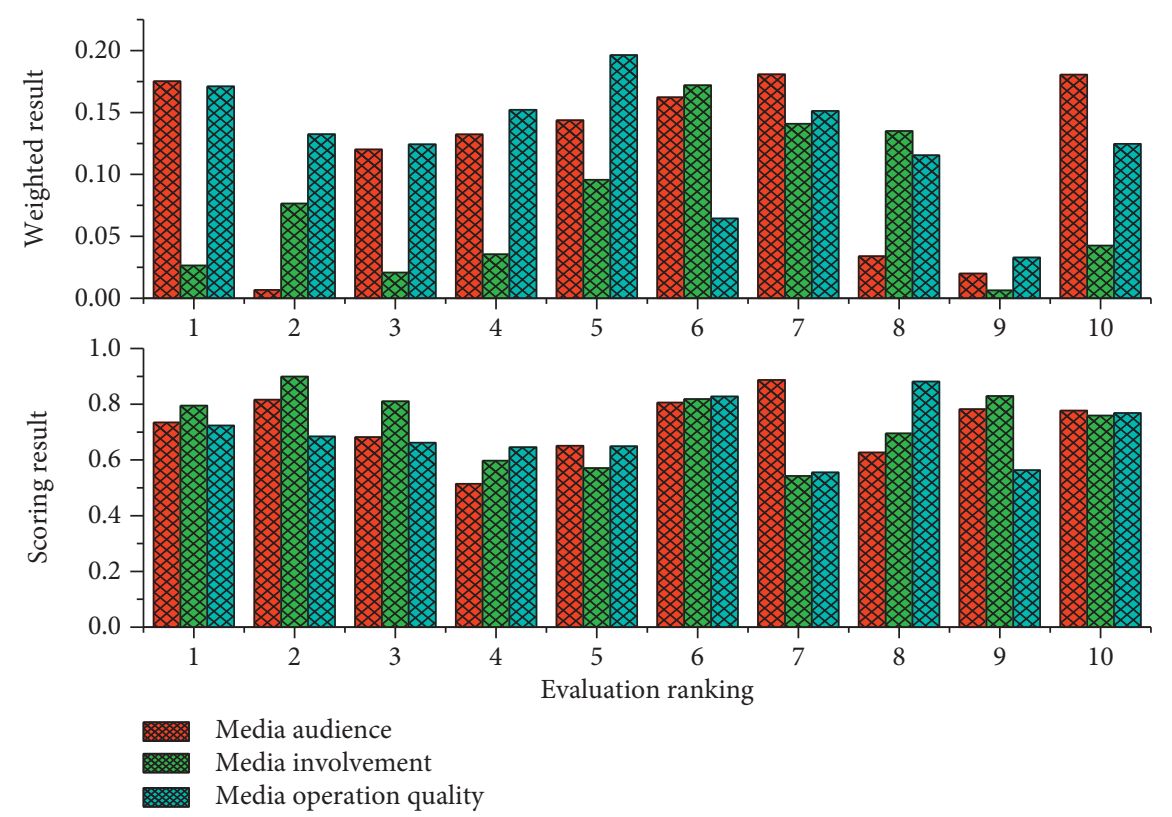

Figure 5: Ranking of indicator classification weights and their scores.

convergent results are also more design-guiding for the computer (Figure 4).

The global weights of all indicators were put together for ranking, and the scores were likewise put together for a comprehensive analysis, as shown in Figure 5. The highest global weight of audience experience is 0.22 , and the lowest weight is education level, which accounts for 0.03 of the global weight, which shows that the education level of the media audience does not necessarily have a significant impact on the advertising performance, but the experience of the media audience significantly affects the advertising performance. The global weights of media acceptance, media reach, and property maintenance are $0.21,0.12$, and 0.06 , all of which are higher than 0.25 and have a great impact on the performance of community outdoor media advertising. They are indicators that have a great impact on the performance of community outdoor media advertising, and their effective control can improve the operational efficiency of media. Ordinary outdoor billboards: billboards without any lighting equipment belong to the early forms of advertising media. With the continuous development and renewal of outdoor media forms, they will be gradually eliminated (Figure 5).

Through the analysis and evaluation of the index system, we also found that the emotion-driven nature of the images is one of the factors that play a significant role in media involvement. The media has already paid attention to this aspect in its current advertising but still needs to be strengthened in the future in terms of image selection and customer selection. Emotion-driven images are the first step to make consumers resonate with the ads they see and therefore affect several factors such as message interactivity and message relevance, which are factors that must be considered in the process of controlling the effectiveness of outdoor media advertising.
4.3. Optimization Effect Analysis. The decrease in attention to outdoor advertising and the decline in attention to outdoor advertising are considered from both audience and advertiser perspectives. The increase in the number of Internet users and the statistics on the length of time spent online indirectly reflect the change in the focus of the audience, who have shifted more time and energy to the Internet and cell phone media. The characteristics and superiority of the Internet and mobile Internet are reflected in the number of Internet users, related business growth, and profound changes in people's living conditions. In 2020, the number of Internet users was 800 million, with a penetration rate of $51.37 \%$, an increase of $1.23 \%$ over the previous year, and the number of cell phone users was 656 million, and the total number of Internet users and cell phone users in China showed a rising trend. In the first half of the year, the weekly Internet access hours per capita was 27.3 hours, an increase of 0.4 hours compared with 2019 (see Figure 6).

With the expansion of Internet users and the increase of Internet users' time on the Internet, advertisers naturally also see this trend, and they will consider the value of media and pay more attention to the marketing effect of advertising and maximizing the value of information dissemination while reducing advertising expenditures, and advertisers begin to put their eyes on new media platforms to obtain effective dissemination of information and timely feedback. According to the core data of online advertising in 2016, the market size of online advertising reached 3984.3 billion yuan, with a year-on-year growth of $36.87 \%$. The market size of mobile advertising reached 2145.1 billion yuan in 2016, with a year-on-year growth rate of $157.3 \%$, and the development momentum was very strong (see Figure 7).

The experiment recruited 100 people to participate in a subjective questionnaire. The questionnaire presented 


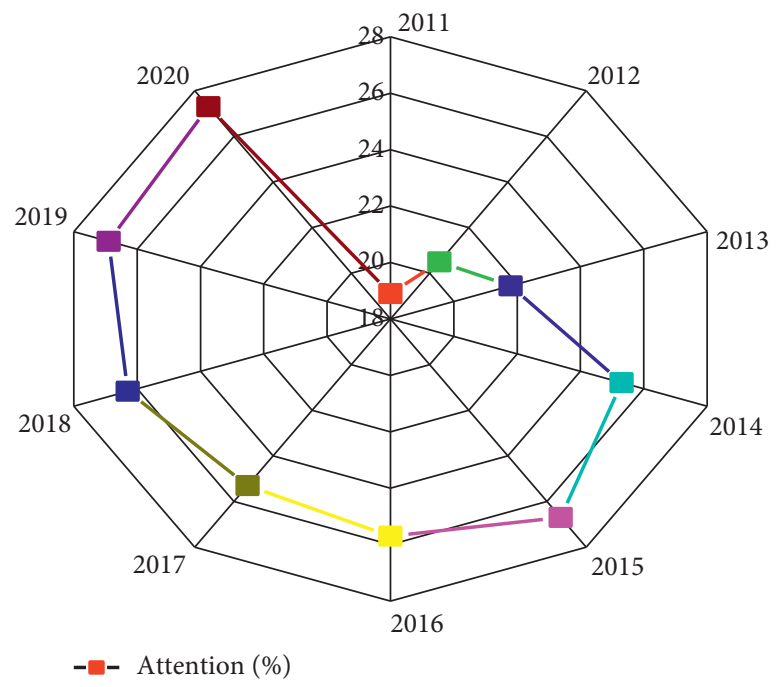

FIgURE 6: The trend of average Internet users' time spent online.
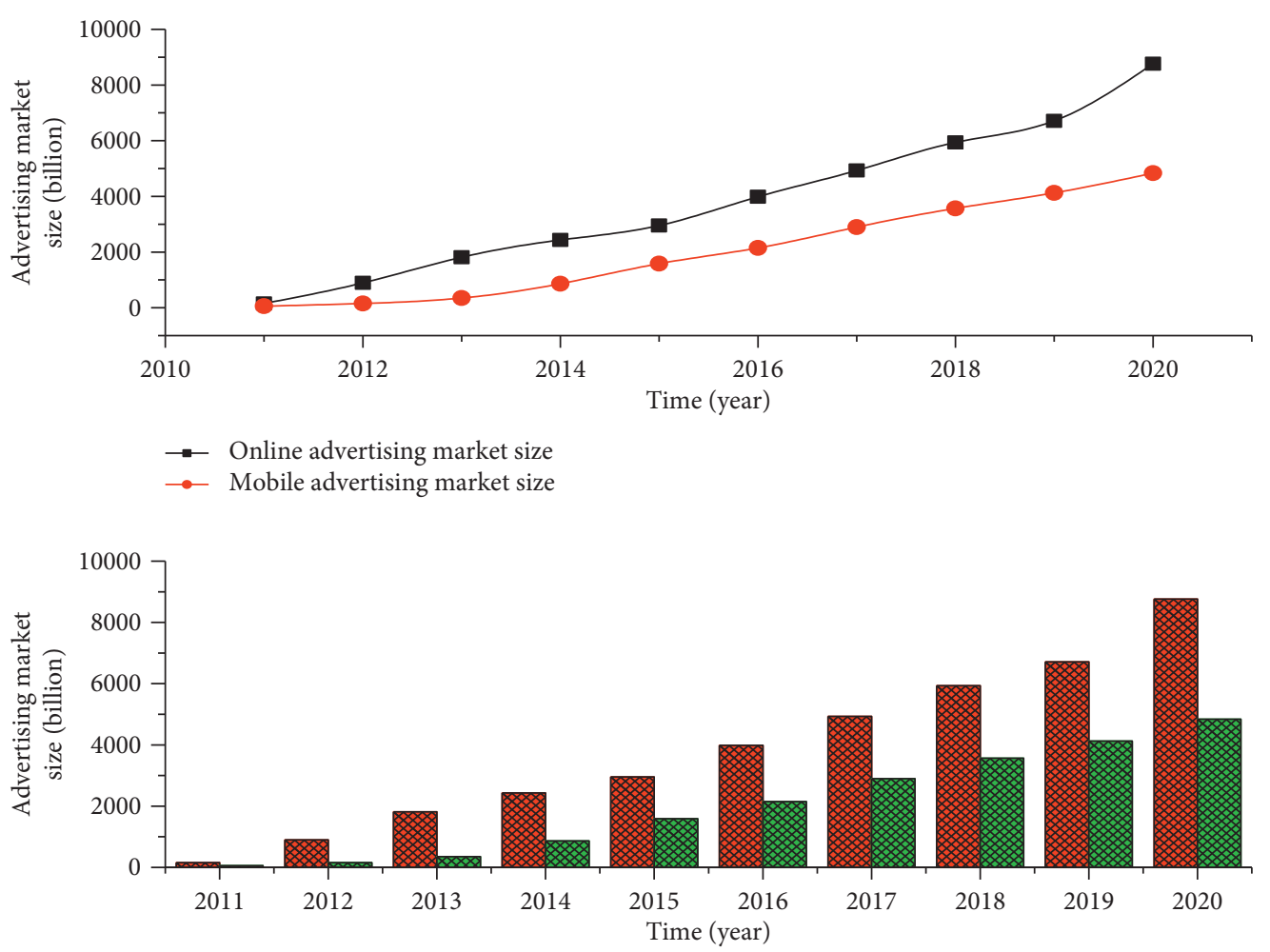

Online advertising market size Mobile advertising market size

FIgURE 7: Outdoor advertising market size and forecast.

participants with 10 color outdoor advertisements of the same layout template each time and asked participants to select 5 outdoor advertisements that they thought had the best color design and 5 outdoor advertisements that had the worst color design. The design results of one of the layout templates were presented twice during the questionnaire to check the consistency of participants' answers. Figure 8 shows the results of the user selection for different color feature models. In this case, red indicates the number of designed outdoor advertisements that users consider to be the best, blue indicates the number of designed outdoor advertisements that they consider to be the worst, and the number of other outdoor advertisements is indicated in yellow (Figure 8). 


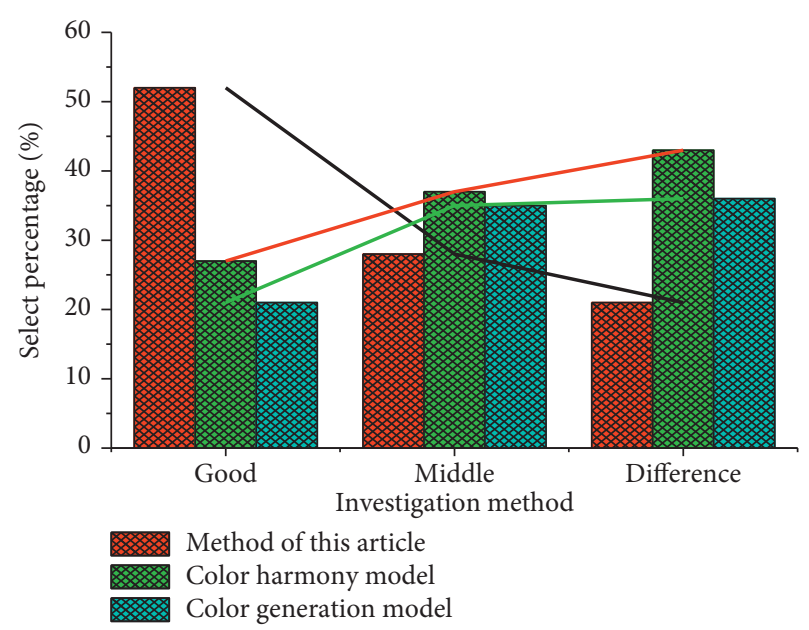

FIgURE 8: Outdoor advertising optimization results.

The social effect produced by new media interactive advertising is mainly the influence of advertising activities on social morality and cultural education. It is difficult to quantify the social effect of new media interactive advertising with a few specific indicators like the evaluation of communication effect and economic effect, because the evaluation of social effect involves all aspects of the whole social environment such as political philosophy, economic form, legal norms, ethics, and morality, which cannot be expressed in specific indicators and values and can only be macroscopically grasped through several aspects such as social influence, buzz, and reputation. The only way to grasp them is through social influence, popularity, and reputation. Similarly, when assessing the social effect of new media interactive advertising, it is also subject to the influence and constraints of social culture in the corresponding social form. Different ideologies and social environments will lead to different results of social evaluation.

\section{Conclusion}

With the development of science and technology, the form of advertising has also ushered in diversified changes. In terms of advertising effects, big data interactive advertising under the sieve of mature data collection, processing, and analysis system avoids the inefficient propaganda mode of traditional advertising indiscriminate casting and starts from the needs of the audience, putting the practicality and entertainment of advertising in the first place. Based on the exploration and research on spiritual civilization, this paper puts the main research direction on the exploration of subjective elements. Starting from the designer's perspective and observing from the audience's perspective, we get some elements that are more in-depth than the original research, making the whole system more fleshed out and the research more comprehensive. Unlike the passive way of audience reception in traditional advertising, new media interactive advertising establishes a more direct way of communication between consumers and products, creates different five senses stimulation and emotional experience environment according to the characteristics of products, and carries out a series of interactions with consumers' sensory systems such as vision, hearing, smell, taste, and touch, which touches consumers' emotional factors, and the way of advertising communication has changed from passive reception to active participation. From the perspective of advertising, the change of advertising communication is interpreting the arrival of a new communication concept, the Internetcentered, and technology-centered data integration era, and we are gradually seeing the huge changes brought by technology and human-centered design to human society and life. Outdoor advertising is facing the impact of new media, on the one hand, to maintain and play its media value and, on the other hand, to actively respond from media competition to media integration. The unique value of outdoor advertising is the intrinsic reason to support its development, and the integration and complementarity between media provide external support for outdoor advertising. I believe that, after the development of the times and the improvement of technology, the outdoor media market will have a better development space in the future.

\section{Data Availability}

The data used to support the findings of this study are included within the article.

\section{Conflicts of Interest}

No conflicts of interest exist concerning this study.

\section{References}

[1] I. Mademlis, V. Mygdalis, N. Nikolaidis et al., "High-level multiple-UAV cinematography tools for covering outdoor events," IEEE Transactions on Broadcasting, vol. 65, no. 3, pp. 627-635, 2019.

[2] C. Campbell, S. Sands, C. Ferraro, H.-Y. Tsao, and A. Mavrommatis, "From data to action: how marketers can leverage AI," Business Horizons, vol. 63, no. 2, pp. 227-243, 2020.

[3] B. Boştină-Bratu, A. Negoescu, and L. Palea, "Consumer acceptance of outdoor advertising: a study of three cities," Land Forces Academy Review, vol. 23, no. 1, pp. 65-74, 2018.

[4] S. Chua and A. Duffy, "Friend, foe or frenemy? Traditional journalism actors' changing attitudes towards peripheral players and their innovations," Media and Communication, vol. 7, no. 4, pp. 112-122, 2019.

[5] U. Kose and P. Vasant, "Better campus life for visually impaired University students: intelligent social walking system with beacon and assistive technologies," Wireless Networks, vol. 26, no. 7, pp. 4789-4803, 2020.

[6] Y. Choi, B. Hickerson, and J. Lee, "Investigation of the technology effects of online travel media on virtual travel experience and behavioral intention," Journal of Travel \& Tourism Marketing, vol. 35, no. 3, pp. 320-335, 2018.

[7] J. Sproul, S. Ledger, and J. MacCallum, "A review of digital media guidelines for students with visual light sensitivity," International Journal of Disability, Development and Education, vol. 68, no. 2, pp. 222-239, 2021.

[8] P. Ozcan and D. Hannah, "Forced ecosystems and digital stepchildren: reconfiguring advertising suppliers to realize 
disruptive social media technology," Strategy Science, vol. 5, no. 3, pp. 193-217, 2020.

[9] U. Stankov, J. Kennell, A. M. Morrison, and M. D. Vujičić, "The view from above: the relevance of shared aerial drone videos for destination marketing," Journal of Travel \& Tourism Marketing, vol. 36, no. 7, pp. 808-822, 2019.

[10] E. Karaaslan, U. Bagci, and F. N. Catbas, "Artificial intelligence assisted infrastructure assessment using mixed reality systems," Transportation Research Record: Journal of the Transportation Research Board, vol. 2673, no. 12, pp. 413-424, 2019.

[11] X. Chen, J. Chen, G. Cheng, and T. Gong, "Topics and trends in artificial intelligence assisted human brain research," PLoS One, vol. 15, no. 4, p. e0231192, 2020.

[12] Y. Feng, Y. Zhao, and H. Zheng, "Data-driven product design toward intelligent manufacturing: a review," International Journal of Advanced Robotic Systems, vol. 17, no. 2, p. 1729881420911257, 2020.

[13] Y. Liu, "Evaluating visitor experience of digital interpretation and presentation technologies at cultural heritage sites: a case study of the old town," Built Heritage, vol. 4, no. 1, pp. 10-15, 2020.

[14] Q. Xie, E. Schauster, and M. S. Neill, "Expectations for advertising and public relations education from agency executives: a comparative study between China and the United States," Journal of Current Issues and Research in Advertising, vol. 39, no. 3, pp. 289-307, 2018.

[15] H. Lee and C.-H. Cho, "Digital advertising: present and future prospects," International Journal of Advertising, vol. 39, no. 3, pp. 332-341, 2020.

[16] G. Monardo, C. Pavese, I. Giorgi, M. Godi, and R. Colombo, "Evaluation of patient motivation and satisfaction during technology-assisted rehabilitation: an experiential review," Games for Health Journal, vol. 10, no. 1, pp. 13-27, 2021.

[17] G. Rosenkrans and K. Myers, "Optimizing location-based mobile advertising using predictive analytics," Journal of Interactive Advertising, vol. 18, no. 1, pp. 43-54, 2018.

[18] W. Nawaz, K. U. Khan, and K. Bashir, "A review on path selection and navigation approaches towards an assisted mobility of visually impaired people," KSII Transactions on Internet and Information Systems (TIIS), vol. 14, no. 8, pp. 3270-3294, 2020.

[19] N. A. F. M. Kamarolzaman, C. F. Yeong, and E. L. M. Su, "Smart advertising robot with image recognition for data analytics," ELEKTRIKA-Journal of Electrical Engineering, vol. 16, no. 3, pp. 11-16, 2017.

[20] C.-C. Huang, "User's segmentation on continued knowledge management system use in the public sector," Journal of Organizational and End User Computing, vol. 32, no. 1, pp. 19-40, 2020.

[21] N. Ramu, V. Pandi, J. D. Lazarus, and S. Radhakrishnan, “A novel trust model for secure group communication in distributed computing," Journal of Organizational and End User Computing, vol. 32, no. 3, pp. 1-14, 2020.

[22] A. Aderonke, "Oni, ugbedeojo musa, samuel oni. E-Revenue adoption in state internal revenue service: interrogating the institutional factors," Journal of Organizational and End User Computing, vol. 32, no. 1, pp. 41-61, 2020.

[23] Z. Cai, Z. He, X. Guan, and Y. Li, "Collective data-sanitization for preventing sensitive information inference attacks in social networks," IEEE Transactions on Dependable and Secure Computing, vol. 15, no. 4, pp. 577-590, 2018.

[24] N. Alvertos, D. Brzakovic, and R. C. Gonzalez, "Camera geometries for image matching in 3-D machine vision," IEEE Transactions on Pattern Analysis and Machine Intelligence, vol. 11, no. 09, pp. 897-915, 1989. 